\title{
APLIKASI CHATBOT BERBASIS WEBSITE SEBAGAI VIRTUAL PERSONAL ASSISTANT DALAM PEMASARAN PROPERTI
}

\author{
Mashud $^{1}$, Wisda $^{2}$ \\ Komputerisasi Akuntansi STMIK AKBA ${ }^{1}$, Sistem Informasi STMIK AKBA ${ }^{2}$ \\ Email :mashud@akba.ac.id ${ }^{1}$,wisda@akba.ac.id ${ }^{2}$
}

\begin{abstract}
ABSTRAK
PT. Tunggal Berjaya Sejahtera adalah salah satu perusahaan di Makassar yang bergerak di bidang properti. PT. Tunggal Berjaya Sejahtera dalam melakukan komunikasi dengan pelanggan melalui via telephone, sms, Facebook, WhatsApp dan media sosial lainnya. Permasalahan yang dihadapi adalah semakin hari jumlah pelanggan yang bertanya semakin banyak dan membutuhkan respon yang cepat. Penelitian ini bertujuan merancang suatu aplikasi chatbot berbasis website yang dapat membantu menjawab pertanyaan pelanggan dengan cepat sehingga pelanggan mendapatkan informasi yang dibutuhkan tanpa membutuhkan waktu dan tenaga dari pegawai. Data Penelitian yang digunakan data primer dan data sekunder. Data primer diperoleh melalu survey dan wawancara, sedangkan data sekunder diperoleh dari dokumen-dokumen perusahaan. Metode perancangan dari sistem ini menggunakan UML (Unifield Modelling Languge) yaitu menggunakan use case diagram, Sequence diagram, Activity diagram, dan Class diagram yang dilengkapi dengan metode pengujian black box untuk fungsional sistem. Dari penelitian dapat menghasilkan aplikasi chatbot berbasis website yang mampu menjawab pertanyaan yang diinputkan oleh pelanggan secara cepat dan tepat. Sehingga memperlancar komunikasi antara PT. Tunggal Berjaya Sejahtera dengan pelanggan dalam pemasaran properti.
\end{abstract}

Kata Kunci: Chatbot; Pemasaran; Properti; Virtual; Website.

\begin{abstract}
ABSTRCT
PT. Tunggal Berjaya Sejahtera is one of the companies in Makassar engaged in property. PT. Tunggal Berjaya Sejahtera in communicating with customers via telephone, sms, Facebook, WhatsApp and other social media. The problem faced is that more and more customers are asking more questions and need a fast response. This study aims to design a website-based chatbot application that can help answer customer questions quickly so that customers get the information they need without the time and effort required from employees. Research Data used primary data and secondary data. Primary data were obtained through surveys and interviews, while secondary data were obtained from company documents. The design method of this system uses UML (Unifield Modeling Languge) using use case diagrams, Sequence diagrams, Activity diagrams, and Class diagrams that are equipped with black box testing methods for functional systems. From research can produce a website-based chatbot application that is able to answer questions submitted by customers quickly and accurately. So as to facilitate communication between PT. Tunggal Berjaya Sejahtera with customers in property marketing.
\end{abstract}

Keywords: Chatbot; Marketing; Property; Virtual; Website. 


\section{PENDAHULUAN}

Perkembangan teknologi sangat ini sangat canggih dan sudah menyentuh segala lini kehidupan termasuk pemasaran properti. Hal itu mendorong banyak peneliti untuk melakukan penelitian teknologi dibidang pemasaran perumahan. Diantaranya penelitian Siti Abidah, Resti Amalia \& Eka Chandra Kirana pada tahun 2014 dengan judul "Desain Sistem Informasi Pemasaran Perumahan Pada PT. Griya Rolanda Mandiri Berbasis Web", penelitian Amirullah \& Megawati pada tahun 2016 dengan judul "Rancang Bangun Sistem Informasi Pemasaran Perumahan Permata Bening Berbasis Web" dan Penelitian Nurul Aini \& Sitti Aisa pada tahun 2018 dengan judul "Aplikasi Brosur Penjualan Rumah Menggunakan Augmented Reality dan Virtual Reality Berbasis Android Pada CV. Aden".

Salah satu teknologi yang banyak dikembangkan untuk mempermudah pekerjaan manusia adalah Virtual Personal Assistant (VPA). Virtual Personal Assistant (VPA) adalah sebuah sistem yang bertindak seperti asisten pribadi, Salah satu bentuk Virtual Personal Assistant (VPA) adalah Chatbot. Sedangkan Virtual Personal Assistant (VPA) itu sendiri merupakan salah satu sistem dari bidang ilmu Kecerdasan buatan (Artificial Intelligence).

Chatbot adalah sebuah program komputer yang dirancang untuk menyimulasikan sebuah percakapan atau komunikasi yang interaktif kepada pelanggan (manusia) melalui bentuk teks, suara, dan atau visual. Percakapan yang terjadi antara komputer dengan manusia merupakan bentuk respon dari program yang telah dideklarasikan pada database program pada komputer. Respon yang dihasilkan merupakan hasil pemindaan dari kata kunci pada inputan pelanggan dan menghasilkan respon balasan yang dianggap paling cocok atau pola kata-kata yang dianggap paling mendekati didalam database. Dalam bahasa sehari-harinya chatbot merupakan Aplikasi atau Program komputer yang dirancang untuk meniru manusia itu sendiri, batasan yang diambil dari chatbot adalah mampu meniru bahasa percakapan pada manusia. Jadi jika manusia sedang bercakap-cakap dengan program ini, maka pelanggan merasa seakan-akan ada dua pribadi manusia yang saling berkomunikasi. Chatbot tersebut sudah dirancang untuk merespon segala jenis pertanyaan dan pernyataan yang di inputkan oleh manusia (pelanggan). Hal ini terjadi karena sebelumnya sudah dideklarasikan pada database, berupa entitas-entitas kata, pola kalimat, dan berbagai jenis pernyataan dan pertanyaan.

PT. Tunggal Berjaya Sejahtera adalah salah satu perusahaan di Makassar yang bergerak di bidang properti. Perkembangan bisnis disertai dengan perkembangan masalah yang makin kompleks, harus dihadapi perusahaan dengan manajemen yang tepat. Salah satu bagian dalam perusahaan yang harus dikelola dengan baik untuk kepentingan internal maupun kepentingan eksternal perusahaan adalah pemasaran. Dalam hal pemasaran PT. Tunggal Berjaya Sejahtera selama ini melakukan komunikasi dengan pelanggan melalui via telephone, sms, Facebook, WhatsApp dan media sosial lainnya. Permasalahan yang dihadapi adalah semakin hari jumlah pelanggan yang bertanya semakin banyak dan membutuhkan respon yang cepat. 


\section{LANDASAN TEORI}

\subsection{Kecerdasan Buatan}

Definisi Kecerdasan Buatan (Artificial Intelligence) merupakan salah satu bagian ilmu komputer yang membuat agar mesin (komputer) dapat melakukan pekerjaan seperti dan sebaik yang dilakukan oleh manusia. Pada awal diciptakannya, komputer hanya difungsikan sebagai alat hitung saja. Namun seiring dengan perkembangan jaman, maka peran komputer semakin mendominasi kehidupan umat manusia. Komputer tidak lagi digunakan sebagai alat hitung, lebih dari itu, komputer diharapkan untuk dapat diberdayakan untuk mengerjakan segala sesuatu yang bisa dikerjakan oleh manusia.

Agar komputer bisa bertindak seperti dan sebaik manusia, maka komputer juga harus diberi bekal pengetahuan, dan mempunyai kemampuan untuk menalar. Untuk itu pada AI, akan mencoba untuk memberikan beberapa metoda untuk membekali komputer dengan kedua komponen tersebut agar komputer bisa menjadi mesin yang pintar (Rohman, 2008).

\subsection{Virtual Personal Assistant}

Virtual Personal Assistant (VPA) adalah sebuah sistem yang bertindak seperti asisten pribadi, melakukan berbagai tugas seperti menemukan informasi serta melaksanakan perintah yang melibatkan aplikasi pada perangkat. Misalnya, menggunakan perintah suara untuk mengatur alarm atau memperbarui kalender dan terlibat dalam obrolan. Zoraida Callejas membagi beberapa karakteristik VPA sebagai berikut: (1). Sistem Dialog, (2). Voice User Interface (VUIs), (3). Chatbot (4). Embodied Conversational Agents (ECAs), ( HB Hakim, 2017)

\subsection{Chatbot}

Chatbot adalah program komputer yang mensimulasikan percakapan cerdas. Proses chatbot dimulai dengan masukan dari pengguna menggunakan bahasa alami dan sistem akan menjawab dengan respon yang masuk akal atau bisa dikatakan cerdas untuk bahasa yang sebenarnya. (Muhajir., A, 2015).

\subsection{Information Retrieval}

Istilah Information Retrieval diciptakan oleh Mooers pada tahun 1951. Information Retrival merupakan bidang persimpangan antara ilmu informasi dan ilmu komputer. ISO 2382/1 mendefinisikan Information Retrieval (IR) sebagai tindakan, metode dan prosedur untuk menemukan kembali data yang tersimpan, kemudian menyediakan informasi mengenai subyek yang dibutuhka. Menurut Gerald J. Kowalski (2002), information retrieval (IR) atau temu balik informasi adalah suatu sistem yang mampu melakukan penyimpanan, pencarian, dan pemeliharaan informasi. Informasi dalam konteks ini dapat terdiri dari teks (termasuk data numerik dan tanggal), gambar, audio, video, dan objek multimedia lainnya. Sedangkan, definisi query dalam sistem IR menurut referensi merupakan sebuah formula yang digunakan untuk mencari informasi yang dibutuhkan oleh user, dalam bentuk yang paling sederhana, sebuah query merupakan suatu keywords (kata kunci) dan dokumen yang mengandung keywords merupakan dokumen yang dicari dalam sistem IR. Tujuan dari sistem IR adalah untuk memenuhi kebutuhan informasi pengguna dengan menemukan kembali semua dokumen yang relevan, pada waktu yang sama menemukan kembali sesedikit mungkin dokumen yang 
tidak relevan. Sistem IR yang baik memungkinkan pengguna menentukan secara cepat dan akurat dokumen mana yang relevan untuk memenuhi kebutuhan pengguna sistem. (Amin, F ,2013).

\subsection{Vector Space Model ( VSM)}

Vector Space Model (VSM) adalah metode untuk melihat tingkat kedekatan atau kesamaan (similarity) term dengan cara pembobotan term. Dokumen dipandang sebagai sebuah vektor yang memiliki magnitude (jarak) dan direction (arah). Pada vector space model, sebuah istilah direpresentasikan dengan sebuah dimensi dari ruang vektor. Relevansi sebuah dokumen ke sebuah kata kuncididasarkan pada similaritas diantara vektor dokumen dan vektor kata kunci. (Amin, F ,2013).

\subsection{Website}

Website adalah lokasi di internet yang menyajikan kumpulan informasi sehubungan dengan profil pemilik situs. Website adalah suatu halaman yang memuat situs-situs web page yang berada di internet yang berfungsi sebagai media penyampaian informasi, komunikasi, atau transaksi. (Hastanti R.P, dkk., 2015).

\subsection{Pemasaran}

Menurut Gronroos, pemasaran adalah mengembangkan, Mempertahankan dan meningkatkan relasi dengan para pelanggan dan mitra lainnya, dengan mendapatkan laba, sedemikian ruapa sehingga tujuan masing-masing pihak tercapai. Sedangkan menurut Vekatesh \& Penaloza pemasaran adalah serangkaian aktivitas yang dilakukan perusahaan untuk menstimulasi permintaan atas produk atau jasanya dan memastikan bahwa produk yang dijual dan disampaikan kepada para pelanggan. (Tjiptono, Fandy, 2008).

\subsection{Properti}

Properti adalah sebuah produk yang dihasilkan atau dibuat oleh sebuah perusahaan properti. Produk properti tersebut dapat berupa perumahan, apartemen, rumah toko (ruko), rumah kantor (rukan), gedung perkantoran (office building), pusat perbelanjaan berupa mall, plaza atau trade center. Perumahan, apartemen, rumah toko (ruko), rumah kantor (rukan), gedung perkantoran (office building) termasuk dalam landed property. Sedangkan mall, plaza atau trade center termasuk dalam commercial building. Dalam penelitian ini akan lebih fokus pada produk properti yaitu perumahan.

Rumah atau papan adalah salah satu kebutuhan dasar manusian yang tingkat kepentingannya hanya dibawah sandang dan pangan. Rumah dapat diartikan sebagai ruang dimana manusia hidup dan melakukan aktifitas kehidupan dan bebas dari dari gangguan fisik maupun psikis. Rumah juga berfungsi sebagai tempat perlindungan dari berbagai macam gangguan iklim serta gangguan dari mahluk hidup lainnya. Perumahan adalah kelompok rumah yang berfungsi sebagai lingkungan tempat tinggal atau lingkungan hunian yang dilengkapi dengan prasarana dan sarana lingkungan.

\subsection{Pemasaran Properti}

Pemasaran properti berfungsi untuk mengarahkan cara-cara pemasaran agar berjalan efektif dan efisien sertab mempercepat proses penjualan. Terdapat beberapa macam cara untuk melakukan tahap pemasaran properti, yaitu (1). Menjual konsep, (2). Membangun hubungan dengan calon konsumen, (3). Referensi, (4). Mitra dan Networking, (5). 
Iklan, (6). Sales dan Telemarketing. (Anditya dan Tito Franky Nasution, 2010).

\section{METODE PENELITIAN}

\subsection{Jenis dan Sumber Data}

Jenis dan sumber data dalam penelitian ini sebagai berikut :

1) Data Primer

Data primer adalah data yang diperoleh melalui hasil penelitian secara langsung terhadap objek yang diteliti. Data primer ini diperoleh melalui hasil survey dan wawancara yang dilakukan.

2) Data Sekunder

Data sekunder adalah data yang diperoleh dari berbagai sumber literature, dokumentasi atau informasi dari pihak yang berhubungan dengan permasalahan dalam penelitian ini. Data sekunder diperoleh dari brosur atau dokumen-dokumen perusahaan yang berhubungan dengan penelitian.

\subsection{Rancangan Model Sistem}

Rancangan sistem merupakan suatu sistem kegiatan yang dilakukan untuk mendesain suatu sistem yang mempunyai tahapan - tahapan kerja yang tersusun secara logis, dimulai dari pengumpulan data yang diperlukan guna pelaksanaan perancangan tersebut. Langkah selanjutnya adalah. Melakukan desain sistem untuk merancang aplikasi chatbot berbasis website sebagai virtual personal assistant dalam pemasaran properti pada PT. Tunggal Berjaya Sejahtera..

Pada perancangan sistem ini dibuat dengan UML terdiri dari use case diagram, Class Diagram, Activity Diagram serta sequence diagram.

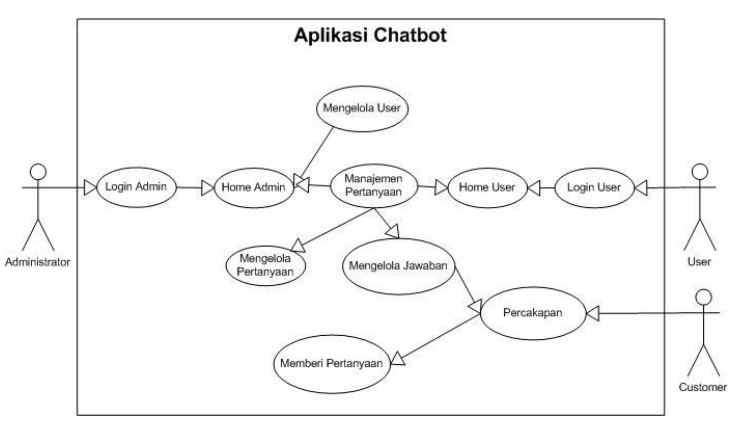

Gambar 1. Use Case Diagram

Gambar 1. merupakan gambar use case diagram pada Aplikasi Chatbot Berbasis Website Sebagai Virtual Personal Assistant Dalam Pemasaran Properti.

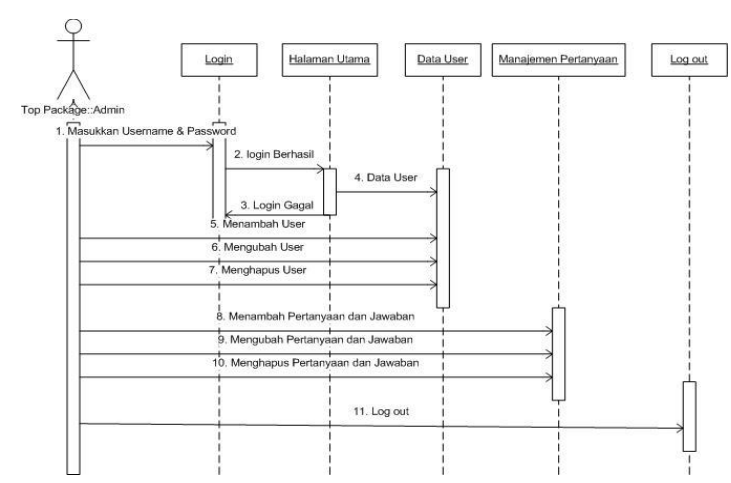

Gambar 2. Sequence Diagram admin

Gambar 2. merupakan gambar Sequence Diagram admin pada Aplikasi Chatbot Berbasis Website Sebagai Virtual Personal Assistant Dalam Pemasaran Properti.

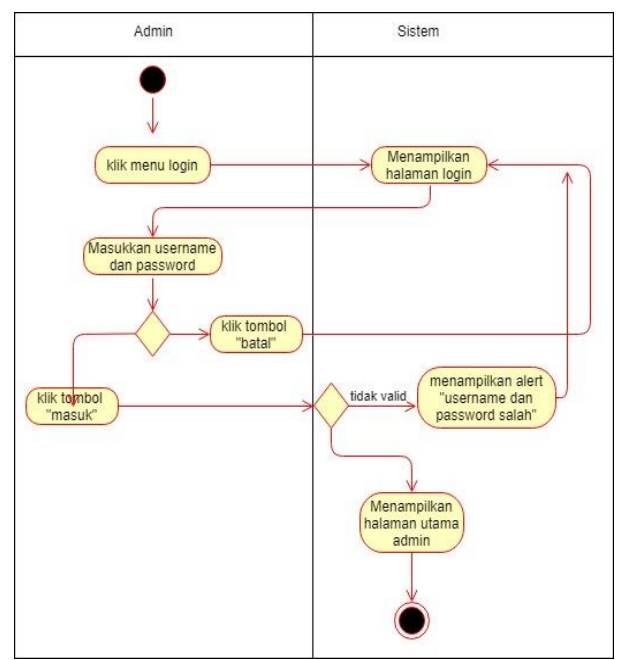

Gambar 3. Activity Diagram 
Gambar 3. merupakan gambar aktivity Diagram login admin pada Aplikasi Chatbot Berbasis Website Sebagai Virtual Personal Assistant Dalam Pemasaran Properti.

\section{HASIL DAN PEMBAHASAN}

4.1. Implementasi

Tahap implementasi merupakan tahap lanjut dari kegiatan perancangan. Tujuan pada tahap ini adalah untuk mengetahui apakah sistem ini dapat dapat berjalan dengan baik sesuai dengan perancangan sistem yang telah dibuat sebelumnya atau belum.

Setelah sistem ini selesai dibuat maka hasilnya berupa apalikasi yang terdiri dari beberapa halaman sebagai berikut :

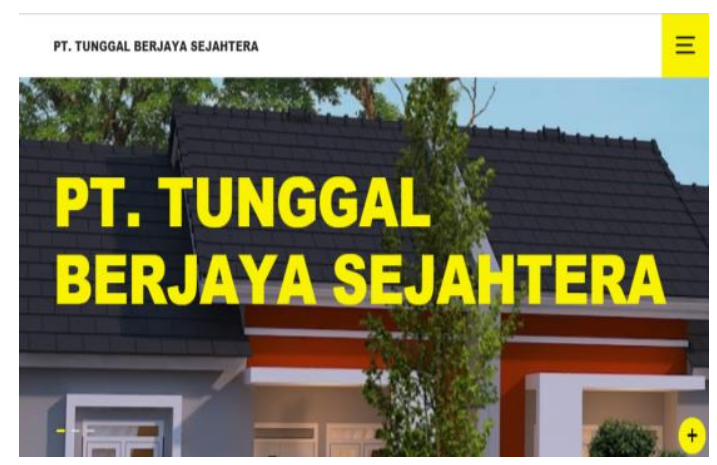

Gambar 4. Halaman Utama

Pada gambar 4. menunjukkan tampilan halaman utama pada Aplikasi Chatbot Berbasis Website Sebagai Virtual Personal Assistant Dalam Pemasaran Properti.

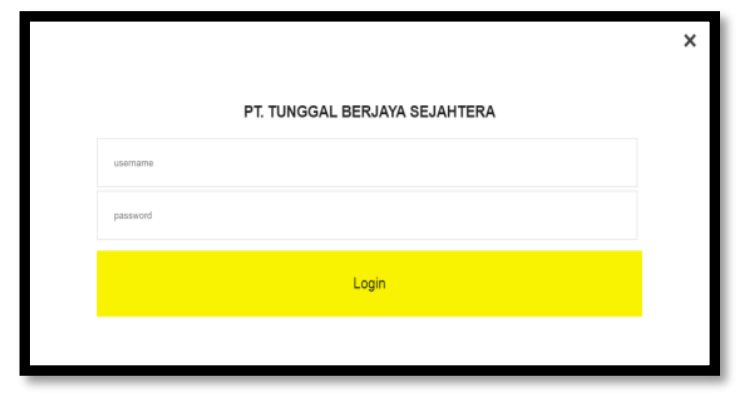

Gambar 5. Halaman Login
Pada gambar 5. menunjukkan tampilan halaman login bagi administrator dan user dengan memasukkan username dan password pada Aplikasi Chatbot Berbasis Website Sebagai Virtual Personal Assistant Dalam Pemasaran Properti.

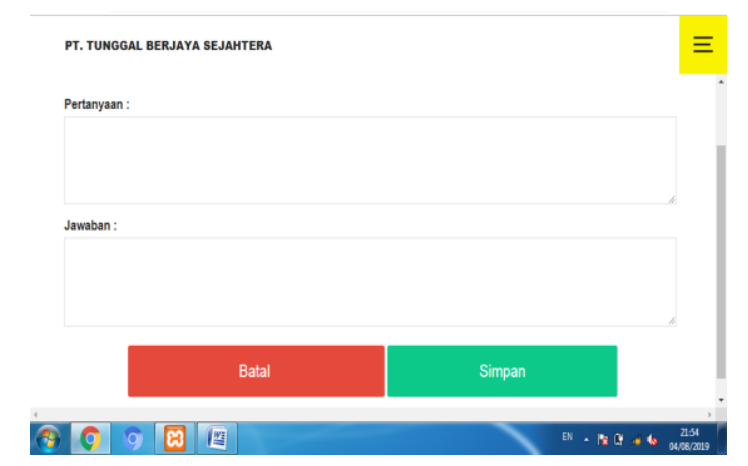

Gambar 6. Tampilan Manajemen Pertanyaan

Pada gambar 6. menunjukkan tampilan Manajemen Pertanyaan bagi administrator dan user dengan memasukkan data-data pertanyaan yang biasa ditanyakan pelanggan dan jawaban pada Aplikasi Chatbot Berbasis Website Sebagai Virtual Personal Assistant Dalam Pemasaran Properti.

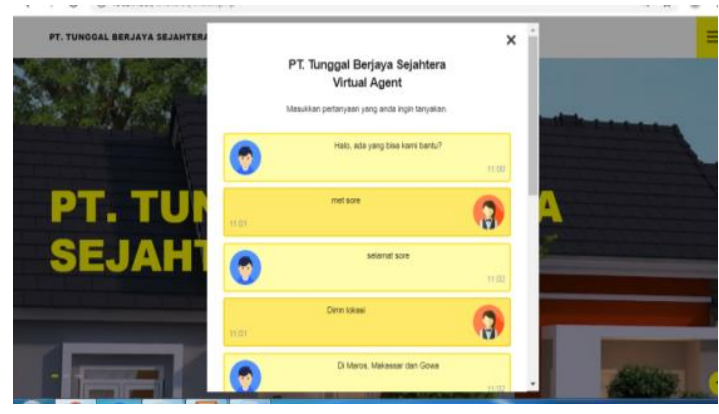

Gambar 7. Tampilan Halaman Chat Pelanggan

Pada gambar 7. menunjukkan tampilan halaman chat bagi pelanggan dengan memasukkan pertanyaan yang biasa ditanyakan dan sistem memberikan jawaban pada Aplikasi Chatbot Berbasis Website Sebagai Virtual Personal Assistant Dalam Pemasaran Properti. 


\subsection{Pengujian}

Tahap pengujian merupakan tahap lanjut setelah tahap implementasi. Berikut pengujian sistem menggunakan metode pengujian blackbox dapat dilihat pada tabel
1 dan untuk pengujian seberapa akurat jawaban yang diberikan oleh sistem chatbot dapat dilihat pada tabel 2 .

Tabel 1. Tabel Pengujian sistem

\begin{tabular}{|c|c|c|c|}
\hline No & Pengujian & $\begin{array}{l}\text { Hasil yang } \\
\text { diharapkan }\end{array}$ & Hasil \\
\hline 1 & $\begin{array}{l}\text { Admin dan user melakukan login dengan } \\
\text { memasukkan username dan password yang benar }\end{array}$ & Login berhasil & $\begin{array}{l}{[\sqrt{ }] \text { Diterima }} \\
{[\text { ]Ditolak }}\end{array}$ \\
\hline 2 & $\begin{array}{l}\text { Admin dan user melakukan login dengan } \\
\text { memasukkan username dan password yang salah }\end{array}$ & Login Gagal & $\begin{array}{l}{[\sqrt{ }] \text { Diterima }} \\
{[\text { ]Ditolak }}\end{array}$ \\
\hline 3 & Admin menambah user & User bertambah & $\begin{array}{l}{[\sqrt{ }] \text { Diterima }} \\
{[\text { ]Ditolak }}\end{array}$ \\
\hline 4 & $\begin{array}{l}\text { Admin dan user menambah data manajemen } \\
\text { pertanyaan }\end{array}$ & $\begin{array}{l}\text { Data manajemen } \\
\text { pertanyaan } \\
\text { bertambah }\end{array}$ & $\begin{array}{l}{[\sqrt{ }] \text { Diterima }} \\
{[\text { ]Ditolak }}\end{array}$ \\
\hline 5 & $\begin{array}{l}\text { Admin dan user mengubah data manajemen } \\
\text { pertanyaan }\end{array}$ & $\begin{array}{l}\text { Data manajemen } \\
\text { pertanyaan berubah }\end{array}$ & $\begin{array}{l}{[\sqrt{ }] \text { Diterima }} \\
{[\text { ]Ditolak }}\end{array}$ \\
\hline 6 & Pelanggan memberikan pertanyaan & $\begin{array}{l}\text { Sistem menjawab } \\
\text { pertanyaan }\end{array}$ & $\begin{array}{l}{[\sqrt{ }] \text { Diterima }} \\
{[\text { ]Ditolak }}\end{array}$ \\
\hline
\end{tabular}

Tabel 2. Tabel pengujian akurasi jawaban sistem chatbot.

\begin{tabular}{|c|c|c|c|}
\hline No & Peranyaan & Jawaban Sistem & Hasil \\
\hline 1 & Selamat Pagi & Selamat Pagi & $\begin{array}{l}{[\sqrt{ }] \text { Diterima }} \\
{[\text { ]Ditolak }}\end{array}$ \\
\hline 2 & Dimana lokasinya? & Maros, Makassar dan Gowa & $\begin{array}{l}{[\sqrt{ }] \text { Diterima }} \\
{[\text { ]Ditolak }}\end{array}$ \\
\hline 3 & $\begin{array}{l}\text { Lokasi } \\
\text { Perumahannya } \\
\text { dimana? }\end{array}$ & Maros, Makassar dan Gowa & $\begin{array}{l}{[\sqrt{ }] \text { Diterima }} \\
{[\text { ]Ditolak }}\end{array}$ \\
\hline 4 & $\begin{array}{l}\text { Dimana anda } \\
\text { sekarang? }\end{array}$ & $\begin{array}{l}\text { Maaf, pertanyaan yang anda masukkan belum } \\
\text { terdapat pada sistem kami. Silahkan masukkan } \\
\text { pertanyaan lain. }\end{array}$ & $\begin{array}{l}{[\sqrt{ }] \text { Diterima }} \\
{[\text { ]Ditolak }}\end{array}$ \\
\hline 5 & Tipe yang ada & Tipe 36 dan Tipe 45 & $\begin{array}{l}{[\sqrt{ }] \text { Diterima }} \\
{[\text { ]Ditolak }}\end{array}$ \\
\hline 6 & Ada photo rumah & $\begin{array}{l}\text { Maaf, pertanyaan yang anda masukkan belum } \\
\text { terdapat pada sistem kami. Silahkan masukkan } \\
\text { pertanyaan lain. }\end{array}$ & $\begin{array}{l}{[\sqrt{ }] \text { Diterima }} \\
{[\text { ]Ditolak }}\end{array}$ \\
\hline 7 & $\begin{array}{l}\text { Apa syarat untuk } \\
\text { kredit? }\end{array}$ & $\begin{array}{l}\text { Photo Copy KTP, Photo Copy Kartu Keluarga, Slip } \\
\text { Gaji Bagi Pegawai, Photo Copy NPWP, Photo } \\
\text { Copy Rekening Bank selama } 3 \text { bulan terakhir. }\end{array}$ & $\begin{array}{l}{[\sqrt{ }] \text { Diterima }} \\
{[\text { ]Ditolak }}\end{array}$ \\
\hline
\end{tabular}




\section{SIMPULAN DAN SARAN}

\subsection{Simpulan}

Setelah melalui tahap perancangan, implementasi dan pengujian, maka dapat ditarik kesimpulan bahwa dengan adanya Aplikasi Chatbot Berbasis Website Sebagai Virtual Personal Assistant mampu menjawab pertanyaan yang diinputkan oleh pelanggan secara cepat dan tepat. Sehingga memperlancar komunikasi antara PT. Tunggal Berjaya Sejahtera dengan pelanggan dalam pemasaran properti.

\subsection{Saran}

Dalam perancangan Aplikasi Chatbot Berbasis Website Sebagai Virtual Personal Assistant ini masih jauh dari sempurna dan masih banyak kekurangan. Oleh karena itu perlu adanya pengembangan lebih lanjut. Adapun saran agar aplikasi ini dapat berfungsi dengan baik adalah sebagai berikut :

1) Mengembangkan Aplikasi Chatbot Berbasis Website Sebagai Virtual Personal Assistant dalam bentuk mobile aplikasi.

2) Menambahkan fitur Maps API pada Aplikasi Chatbot Berbasis Website Sebagai Virtual Personal Assistant sehingga pelanggan dengan mudah menemukan properti yang dipasarkan.

3) Menambahkan fitur pengiriman gambar pada Aplikasi Chatbot Berbasis Website Sebagai Virtual Personal Assistant sehingga pelanggan dengan mudah melihat bentuk properti yang dipasarkan.

\section{UCAPAN TERIMA KASIH}

Peneliti mengucapkan terima kasih kepada Direktorat Riset dan Teknologi Kemenristekdikti atas dukungan dana pada penelitian ini . Peneliti juga berterima kasih kepada P3M STMIK AKBA atas motivasi dalam penelitian.

\section{DAFTAR PUSTAKA}

Abida. S. dkk. (2014). Desain Sistem Informasi Pemasaran Perumahan Pada PT. Griya Rolanda Mandiri Berbasis Web. PROGRESIF Vol. 10, No. 2, Agustus 2014 : 1017 1076

Aini. N. \& Sitti Aisa. (2018). Aplikasi Brosur Penjualan Rumah Menggunakan Augmented Reality dan Virtual Reality Berbasis Android Pada CV. Aden. Seminar Nasional Sistem Informasi dan Teknologi Informasi 2018. SENSITEK 2018. STMIK Pontianak. Hal 127-131.

Amin, F. (2013). Sistem Temu Kembali Informasi dengan Pemeringkatan Metode Vector Space Model. Jurnal Teknologi Informasi DINAMIK, 18(2), 122-129.

Amirullah \& Megawati. (2016). Rancang Bangun Sistem Informasi Pemasaran Perumahan Permata Bening Berbasis Web. Jurnal Ilmiah Rekayasa dan Manajemen Sistem Informasi, Vol. 2, No. 2, Agustus 2016. e-ISSN 2502-8995 p-ISSN 2460-8181.

Anditya \& Tito Franky Nasution. (2010). Trik Sukses Menjadi Pengusaha Properti, Penerbit CV. Andi Offset, Yogyakarta.

Hastanti R.P, dkk. (2015). Sistem Penjualan Berbasis Web (ECommerce) Pada Tata Distro Kabupaten Pacitan, Jurnal Bianglala Informatika Vol 3 No 2.

HB Hakim. (2017). Rancang Bangun Aplikasi Personal Assistant Memanfaatkan Live 2D Seabagai User Interface Pada Android, 
Universitas Muhammadiyah Malang

Muhajir., A. (2015). Pengembangan a.l.i.c.e sebagai chatbot pakar jaringan komputer menggunakan supervise (direct teaching) dan unsupervice learning (summary base knowladge menggunakan metode tf-idf).
Rohman. (2008). Rancang bangun aplikasi sistem pakar untuk menentukan jenis gangguan perkembangan, 6(1), 1-23.

Tjiptono, Fandy, (2008). Strategi Pemasaran, Edisi 3, ANDI: Yogyakarta 